\title{
MATRIKS BAKU UNTUK TRANSFORMASI LINIER PADA RUANG VEKTOR DIMENSI TIGA
}

\author{
Standard Matrix for Linear Transformation in Three Dimensional Vector \\ Khasnah Aris Friantika ${ }^{1}$, Harina O. L. Monim ${ }^{2}$, Rium Hilum ${ }^{3}$ \\ ${ }^{123}$ Jurusan Matematika, Fakultas Matematika dan Ilmu Pengetahuan Alam, UNIPA, Manokwari, 98314, \\ Email: arisceriaselalu@gmail.com
}

\begin{abstract}
The linear transformation is a function relating the vector $R^{\mathrm{n}}$ ke $R^{\mathrm{m}}$. If $R^{\mathrm{n}}=R^{\mathrm{m}}$, then the transformation is called a linear operator. Several examples of linear operators have been introduced since SMA such as reflexive, rotation, compression and expansion and shear. Apart from being introduced in SMA, these linear operators were also introduced to the linear algebra course. Linear transformations studied at the university level include linear transformation in finite dimension vector spaces $n=2$. The discussion includes how to determine the standard matrix for reflexive linear transformations, rotation, compression and expansion and given shear. Through the column vectors of reflexive, rotation, compression and expansion and shear, a standard matrix of $2 \times 2$ size is formed for the corresponding linear transformation. however, in this study, the authors studied linear transformations in dimensioned vector spaces $n=3$. The results of this study are if known $R^{3}$ is a vector space with finite and $(x, y, z) \in R^{3}$ the standard matrix for reflexivity, rotation, expansion, compression and shear is obtained. Each of these linear transformations is performed on x-axis, y-axis and z-axis on $R^{3}$ to get column vectors. The column vectors as a result of the linear transformation at $R^{3}$ form the standard matrix for the corresponding linear transformation in the vector space $R^{3}$. The standard matrix for linear transformations in the vector space $R^{3}$ is obtained by determining reflexivity, rotation, expansion, compression and shear. The process of obtaining a standard matrix for linear transformation is carried out by rewriting the standard basis, determining the column vectors, and rearranging them as the standard matrix for each linear transformation in the vector space $R^{3}$
\end{abstract}

Keywords: standard matrix, linear transformation, three dimensional vector space.

\begin{abstract}
ABSTRAK
Transformasi linier adalah fungsi yang mengaitkan ruang vektor $R^{\mathrm{n}} \mathrm{ke} R^{\mathrm{m}}$. Jika $R^{\mathrm{n}}=R^{\mathrm{m}}$, maka transformasi disebut operator linier. Beberapa contoh operator linier telah diperkenalkan sejak SMA seperti refleksif, rotasi, kompresi dan ekspansi serta geseran. Selain diperkenalkan di SMA, operator-operator linier ini juga diperkenalkan pada mata kuliah aljabar linier. Trasformasi linier yang dipelajari ditingkat universitas diataranya transfomasi linier pada ruang vektor berdimesi hingga $n=2$. Pembahasan meliputi bagaimana menentukan matriks baku untuk transformasi linier refleksif, rotasi, kompresi dan ekspansi serta geseran yang diberikan. Melalui vektor -vektor kolom dari refleksif, rotasi, kompresi dan ekspansi serta geseran dibentuk matriks baku-matriks baku berukuran $2 \times 2$ untuk transformasi linier yang bersesuaian. namun pada penelitian ini, penulis mengkaji transformasi linier pada ruang vektor berdimesi $n=3$. Hasil
\end{abstract}


penelitian ini adalah jika diketahui $R^{3}$ merupakan ruang vektor berdimensi hingga dan $(x, y, z) \in R^{3}$ maka diperoleh matriks baku untuk refleksif, rotasi, ekspansi, kompresi dan geseran. Masing-masing transformasi linier ini dilakukan terhadap sumbu- $x$, sumbu- $y$ dan sumbu- $z$ pada $R^{3}$ untuk medapatkan vektor-vektor kolom. Vektor-vektor kolom sebagai hasil transformasi linier pada $R^{3}$ membentuk matriks baku untuk transformasi linier yang bersesuaian pada ruang vektor $R^{3}$. Matriks baku untuk transformasi linier pada ruang vektor $R^{3}$ diperoleh dengan menentukan refleksif, rotasi, ekspansi, kompresi serta geseran. Proses dalam memperoleh matriks baku untuk transformasi linier dilakukakan dengan menuliskan kembali basis baku, menentukan vektor-vektor kolom, dan menyusun kembali sebagai matriks baku untuk setiap transformasi linier pada ruang vektor $R^{3}$.

Kata Kunci: matriks baku, transformasi linier, ruang vektor dimensi tiga.

\section{PENDAHULUAN}

Transformasi linier adalah fungsi yang mengaitkan ruang vektor $R^{\mathrm{n}}$ ke $R^{\mathrm{m}}$. Jika $R^{\mathrm{n}}=R^{\mathrm{m}}$, maka transformasi disebut operator linier. Beberapa contoh operator linier telah diperkenalkan sejak SMA seperti refleksif, rotasi, kompresi dan ekspansi serta geseran. Selain diperkenalkan di SMA, operatoroperator linier ini juga diperkenalkan pada mata kuliah aljabar linier.

Trasformasi linier yang dipelajari ditingkat universitas diataranya transfomasi linier pada ruang vektor berdimesi hingga $n=2$. Pembahasan meliputi bagaimana menentukan matriks baku untuk transformasi linier refleksif, rotasi, kompresi dan ekspansi serta geseran yang diberikan. Melalui vektor vektor kolom dari refleksif, rotasi, kompresi dan ekspansi serta geseran dibentuk matriks baku-matriks baku berukuran $2 \times 2$ untuk transformasi linier yang bersesuaian. namun pada penelitian ini, penulis mengkaji transformasi linier pada ruang vektor berdimesi $n=3$.

\section{METODE PENELITIAN}

Metode yang digunakan pada penelitian ini adalah vektor-vektor kolom sebagai hasil transformasi linier pada ruang vektor $R^{3}$. Seperti Gambar 1 . 


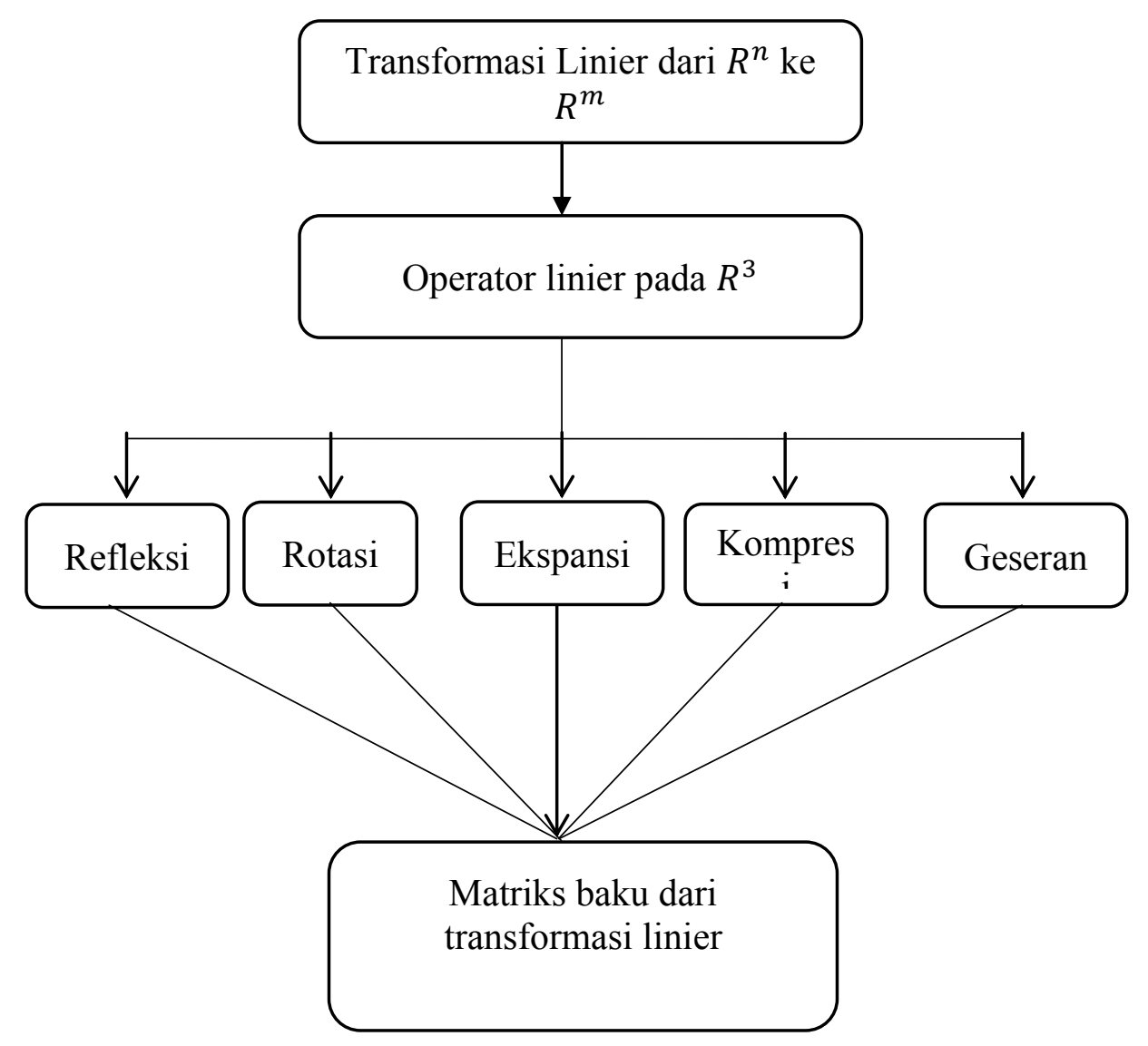

Evaluasi matriks baku dari transformasi linier

Gambar 1. Diagram prosedur penelitian.

\section{HASIL DAN PEMBAHASAN}

Hasil penelitian ini adalah jika diketahui $R^{3}$ merupakan ruang vektor berdimensi hingga dan $(x, y, z) \in R^{3}$ maka diperoleh matriks baku untuk refleksif, rotasi, ekspansi, kompresi dan geseran. Masing-masing transformasi linier ini dilakukan terhadap sumbu- $x$, sumbu- $y$ dan sumbu- $z$ pada $R^{3}$ untuk medapatkan vektor-vektor kolom. Vektor-vektor kolom sebagai hasil transformasi linier pada $R^{3}$ membentuk matriks baku untuk transformasi linier yang bersesuaian pada ruang vektor $R^{3}$. Hasil transformasi akan disajikan pada Tabel 1 sampai Tabel 4. 
Tabel 1 Matriks baku untuk refleksi pada ruang vektor dimensi tiga

\begin{tabular}{ccc}
\hline Transformasi & Definisi & Matriks baku \\
\hline $\begin{array}{c}\text { Refleksi sumbu- } x \\
\text { positif }\end{array}$ & $T\left(\left[\begin{array}{l}x \\
y \\
z\end{array}\right]\right)=\left[\begin{array}{c}x \\
-y \\
z\end{array}\right]$ & $A=\left[\begin{array}{ccc}1 & 0 & 0 \\
0 & -1 & 0 \\
0 & 0 & 1\end{array}\right]$ \\
$\begin{array}{c}\text { Refleksi sumbu- } y \\
\text { positif }\end{array}$ & $T\left(\left[\begin{array}{l}x \\
y \\
z\end{array}\right]\right)=\left[\begin{array}{c}x \\
y \\
-z\end{array}\right]$ & $A=\left[\begin{array}{ccc}1 & 0 & 0 \\
0 & 1 & 0 \\
0 & 0 & -1\end{array}\right]$
\end{tabular}

\begin{tabular}{ccc}
\hline \multicolumn{2}{l}{ Tabel 2 Matriks baku untuk rotasi pada ruang vektor dimensi tiga } \\
\hline $\begin{array}{c}\text { Transformasi } \\
\text { positif }\end{array}$ & $T(u)=\left[\begin{array}{l}x \\
y \\
z\end{array}\right]=\left[\begin{array}{r}x \\
r \cos (\alpha+\varphi) \\
r \sin (\alpha+\varphi)\end{array}\right]$ & $A=\left[\begin{array}{ccc}1 & 0 & 0 \\
0 & \cos \alpha & -\sin \alpha \\
0 & \sin \alpha & \cos \alpha\end{array}\right]$ \\
$\begin{array}{c}\text { Rotasi sumbu- } y \\
\text { positif }\end{array}$ & $T(u)=\left[\begin{array}{l}x \\
y \\
z\end{array}\right]=\left[\begin{array}{c}r \sin (\alpha+\varphi) \\
y \\
r \cos (\alpha+\varphi)\end{array}\right]$ & $A=\left[\begin{array}{ccc}\cos \alpha & 0 & \sin \alpha \\
0 & 1 & 0 \\
-\sin \alpha & 0 & \cos \alpha\end{array}\right]$ \\
$\begin{array}{c}\text { Rotasi sumbu- } z \\
\text { positif }\end{array}$ & $T(u)=\left[\begin{array}{l}x \\
y \\
z\end{array}\right]=\left[\begin{array}{r}r \cos (\alpha+\varphi) \\
r \sin (\alpha+\varphi) \\
z\end{array}\right]$ & $A=\left[\begin{array}{ccc}\cos \alpha & -\sin \alpha & 0 \\
\sin \alpha & \cos \alpha & 0 \\
0 & 0 & 1\end{array}\right]$. \\
\end{tabular}

Tabel 3 Matriks baku untuk kompresi dan ekspansi pada ruang vektor dimensi tiga

\begin{tabular}{|c|c|c|}
\hline Transformasi & Definisi & Matriks baku \\
\hline $\begin{array}{l}\text { Kompresi sumbu- } x \\
\text { positif }\end{array}$ & $T\left[\begin{array}{l}x \\
y \\
z\end{array}\right]=\left[\begin{array}{c}k x \\
y \\
z\end{array}\right]$ & $A=\left[\begin{array}{lll}k & 0 & 0 \\
0 & 1 & 0 \\
0 & 0 & 1\end{array}\right]$ \\
\hline $\begin{array}{l}\text { Kompresi sumbu-y } \\
\text { positif }\end{array}$ & $T\left[\begin{array}{l}x \\
y \\
z\end{array}\right]=\left[\begin{array}{c}x \\
k y \\
z\end{array}\right]$ & $A=\left[\begin{array}{lll}1 & 0 & 0 \\
0 & k & 0 \\
0 & 0 & 1\end{array}\right]$ \\
\hline $\begin{array}{l}\text { Kompresi sumbu-Z } \\
\text { positif }\end{array}$ & $T\left[\begin{array}{l}x \\
y \\
z\end{array}\right]=\left[\begin{array}{c}x \\
y \\
k z\end{array}\right]$ & $A=\left[\begin{array}{lll}1 & 0 & 0 \\
0 & 1 & 0 \\
0 & 0 & k\end{array}\right]$ \\
\hline $\begin{array}{l}\text { Ekspansi sumbu- } x \\
\text { positif }\end{array}$ & $T\left[\begin{array}{l}x \\
y \\
z\end{array}\right]=\left[\begin{array}{c}k x \\
y \\
z\end{array}\right]$ & $A=\left[\begin{array}{lll}k & 0 & 0 \\
0 & 1 & 0 \\
0 & 0 & 1\end{array}\right]$ \\
\hline $\begin{array}{l}\text { Ekspansi sumbu- } y \\
\text { positif }\end{array}$ & $T\left[\begin{array}{l}x \\
y \\
z\end{array}\right]=\left[\begin{array}{c}x \\
k y \\
z\end{array}\right]$ & $A=\left[\begin{array}{lll}1 & 0 & 0 \\
0 & k & 0 \\
0 & 0 & 1\end{array}\right]$ \\
\hline $\begin{array}{c}\text { Ekspansi sumbu- } Z \\
\text { positif }\end{array}$ & $T\left[\begin{array}{l}x \\
y \\
z\end{array}\right]=\left[\begin{array}{c}x \\
y \\
k z\end{array}\right]$ & $A=\left[\begin{array}{lll}1 & 0 & 0 \\
0 & 1 & 0 \\
0 & 0 & k\end{array}\right]$ \\
\hline
\end{tabular}


Tabel 4 Matriks baku untuk geseran pada ruang vektor dimensi tiga

\begin{tabular}{ccc}
\hline Transformasi & Definisi & Matriks baku \\
\hline $\begin{array}{c}\text { Geseran sumbu- } x \\
\text { positif }\end{array}$ & $T\left[\begin{array}{l}x \\
y \\
z\end{array}\right]=\left[\begin{array}{c}x+k z \\
0 \\
z\end{array}\right]$ & $A=\left[\begin{array}{lll}1 & 0 & k \\
0 & 1 & 0 \\
0 & 0 & 1\end{array}\right]$. \\
$\begin{array}{c}\text { Geseran sumbu- } y \\
\text { positif }\end{array}$ & $T\left[\begin{array}{l}x \\
y \\
z\end{array}\right]=\left[\begin{array}{c}0 \\
y+k z \\
z\end{array}\right]$ & $A=\left[\begin{array}{lll}1 & 0 & 0 \\
0 & 1 & k \\
0 & 0 & 1\end{array}\right]$. \\
$\begin{array}{c}\text { Geseran sumbu- } z \\
\text { positif }\end{array}$ & $T\left(\left[\begin{array}{l}x \\
y \\
z\end{array}\right]\right)=\left[\begin{array}{c}0 \\
y \\
k y+z\end{array}\right]$ & $A=\left[\begin{array}{lll}0 & 0 & 0 \\
0 & 1 & 0 \\
0 & k & 1\end{array}\right]$. \\
\end{tabular}

\section{KESIMPULAN}

Matriks baku untuk transformasi linier pada ruang vektor $R^{3}$ diperoleh dengan menentukan refleksif, rotasi, ekspansi, kompresi serta geseran. Proses dalam memperoleh matriks baku untuk transformasi linier dilakukakan dengan menuliskan kembali basis baku, menentukan vektor-vektor kolom, dan menyusun kembali sebagai matriks baku untuk setiap transformasi linier pada ruang vektor $R^{3}$.

\section{DAFTAR PUSTAKA}

Abdul, A. M., Yanita., Noliza, N. B. 2019. Sifat-sifat Matriks Ortogonal dan Transformasi Ortogonal. Jurnal Matematika UNAND. Jurusan Matematika dan Ilmu Pengetahuan Alam. Universitas Andalas. Vol 8 (2): 7-14.

Anton, H. 1987. Dasar-dasar Aljabar Linear. Edisi Kelima. Penerjemah:
Susila I.N., Silaban P. Penerbit Erlangga. Jakarta.

. 2008. Dasar-dasar Aljabar Linier. Penerjemah: Susila I.N., Silaban P. Penerbit Erlangga. Jakarta.

Anton, H., Rorres, C. 2005. Aljabar Linear Elementer. Edisi kedua. Penerbit Erlangga. Jakarta.

Budhi, W.S. 1995. Aljabar Linear. Gramedia Pustaka Umum. Jakarta.

Cooke, R.L. 2013. The History of Mathematics A Brief Course. $3^{\text {rd }}$ Ed. New York: John Wiley dan Sons, Inc.

Dwi, A.K., Pramudya, I. 2018. Pencerminan Pada Dimensi Tiga. Journal of Mathematics and Mathematics Education. Universitas Sebelas Maret. Vol 8 (2): 79-84.

Leon, S.J. 2001. Aljabar Linear dan Aplikasinya. Edisi . Penerbit Erlangga. Jakarta. 
Lipschuts, S., Lipson, M. 2006. Aljabar Linear. Edisi Ketiga. Penerbit Erlangga. Jakarta.

Manda, I.S. 2011. Kombinasi Linier dan Transformasi dari Fungsi Harmonik. Skripsi. Jurusan Matematika dan Statistika. Universitas Papua. Manokwari.

Mortonson, M.E. 1996. Geometri Modeling. John Wiley dan Sons, Inc. New York.
Purcell, E.J., Varberg, D., Rigdon, S.E. 2004. Kalkulus. Penerbit Erlangga. Jakarta.

Santoso, R.G. 2009. Aljabar Linier Dasar. Penerbit Andi. Yogyakarta.

Sutojo, T., Bowo, N. 2009. Aljabar Linear dan Matriks. Edisi Kesatu. Penerbit Andi. Semarang.

Tampomas, H. 2006. Seribu Pena Matematika SMA. Edisi Ketiga. Penerbit Erlangga. Jakarta. 